\title{
Shear Amorphization of Boron Suboxide
}

\author{
K. Madhav Reddy, ${ }^{a}$ A. Hirata, ${ }^{a}$ P. Liu, ${ }^{a}$ T. Fujita, ${ }^{a}$ T. Goto ${ }^{b}$ and M. W. Chen ${ }^{a}{ }^{* *}$ \\ ${ }^{a}$ WPI Advanced Institute for Materials Research, Tohoku University, Sendai 980-8577, Japan \\ ${ }^{\mathrm{b}}$ Institute for Materials Research, Tohoku University, Sendai 980-8577, Japan \\ ${ }^{\mathrm{c}}$ State Key Laboratory of Metal Matrix Composites, School of Materials Science and \\ Engineering, Shanghai Jiao Tong University, Shanghai 200030, PR China
}

\begin{abstract}
We report for the first time the shear-induced local amorphization of boron suboxide subjected to nanoindentation. The amorphous bands have a width of $\sim 1-3 \mathrm{~nm}$ and length of 200-300 $\mathrm{nm}$ along the $(0 \overline{1} 11)$ crystal plane. We show the direct experimental evidence that the amorphous shear bands of boron suboxide is driven from the coalescence of dislocation loops at high shear stresses. These observations provide the microscopic insights into the deformation and failure of the high-strength and lightweight ceramics.
\end{abstract}

*Corresponding author: E-mail: (mwchen@wpi-aimr.tohoku.ac.jp). Phone: 8122217 5959;

Fax: 81222175955

Keywords: Boron suboxide ceramic; Nanoindentation; Transmission electron microscopy; Amorphization 
Super-hard materials with strong covalent bonds often fail in a brittle manner dominated by normal stresses at room temperature. The low-density boron suboxide $\left(\mathrm{B}_{6} \mathrm{O}\right)$ is one of the super-hard materials with the hardness comparable to boron carbide $\left(\mathrm{B}_{4} \mathrm{C}\right)$ and cubic boron nitride $(\mathrm{BN})$ ceramics [1-5]. The unusual hardness of $\mathrm{B}_{6} \mathrm{O}$ comes from its basic structure that composes of icosahedra $\left(\mathrm{B}_{12}\right)$ and two oxygen $(\mathrm{O}-\mathrm{O})$ atom chain at the center of the rhombohedral, which is similar to 12 -atom icosahedra and a three-atom chain distribution in $\mathrm{B}_{4} \mathrm{C}$ [6-10]. Unlike $\mathrm{B}_{4} \mathrm{C}$ and $\mathrm{BN}$ that have been widely used in industry, $\mathrm{B}_{6} \mathrm{O}$ have not been commercialized so far partially because of the difficulty in obtaining full densification using conventional sintering methods. Therefore, the basic properties of this ceramic material have not been completely studied [4, 11-13]. The potential applications of the $\mathrm{B}_{6} \mathrm{O}$ ceramic in wear and hard facing parts could be realized by understanding the underlying deformation and failure mechanisms at high contact pressures. In this letter, for the first time, we report the microscopic evidence of amorphous $\mathrm{B}_{6} \mathrm{O}$ that was produced by nanoindentation, indicating the failure of $\mathrm{B}_{6} \mathrm{O}$ is associated with the shear amorphization.

$\mathrm{B}_{6} \mathrm{O}$ powders were synthesized from the mixture of crystalline boron $(\beta-\mathrm{B})$ and amorphous boron oxide $\left(\mathrm{B}_{2} \mathrm{O}_{3}\right)$ by a solid-liquid reaction. The obtained $\mathrm{B}_{6} \mathrm{O}$ powders were consolidated by the hot press technique at $2173 \mathrm{~K}, 60 \mathrm{MPa}$ for $1 \mathrm{~h}$. A detailed synthesis procedure can be found in the previous report [14]. The relative density of bulk $\mathrm{B}_{6} \mathrm{O}$ is $\sim 97.5 \%\left(2.55 \mathrm{~g} / \mathrm{cm}^{3}\right)$ of theoretical density $\left(2.62 \mathrm{~g} / \mathrm{cm}^{3}\right)$. A series of indentation tests were performed on smoothly polished $\mathrm{B}_{6} \mathrm{O}$ surface at constant loading force $(1 \mathrm{~N})$ and loading rate $(\sim 14 \mathrm{mN} / \mathrm{s})$ using a dynamic ultra-micro-hardness tester (Shimadzu W201S) equipped with a berkovich diamond indenter. The measured average hardness value was $~ 38 \mathrm{GPa}$. Raman spectra were collected using a Renishaw 1000 with the excitation wavelength of $633 \mathrm{~nm}$ of an argon laser source. The beam size of the laser spot is about $1 \mu \mathrm{m}$. As sintered $\mathrm{B}_{6} \mathrm{O}$ TEM specimen was sliced from bulk and mechanically ground to $\sim 150 \mu \mathrm{m}$. The surface of the thin 
specimen was then dimpled to a thickness of about $20 \mu \mathrm{m}$ and ion-beam milled to obtain electron transparency (Fischione 1010 Model). The cross sectional TEM specimens of the indented $\mathrm{B}_{6} \mathrm{O}$ samples were prepared by lift-out technique using a focused ion beam milling (FIB) system (JEOL JIB-4600F) [15]. The cross-sectional indentation samples were subjected to a low voltage ion milling (i.e. $900 \mathrm{~V}$ ) in a Fischone 1040 Nanomill system to remove the damage layers without altering surface chemistry before the TEM analysis. The microstructures of the as-prepared and deformed samples were characterized with a JEOL JEM-2100F transmission electron microscope equipped with Gatan imaging system for electron energy loss spectroscopy.

A typical TEM image of the as-sintered $\mathrm{B}_{6} \mathrm{O}$ ceramic shows fine and tight grained microstructure (Figure 1). The grain size distribution of $\mathrm{B}_{6} \mathrm{O}$ ranges from $100 \mathrm{~nm}$ to $2 \mu \mathrm{m}$ with a mean size (std. dev) of about $400( \pm 190) \mathrm{nm}$. Numerous stacking faults and twin bands in $\mathrm{B}_{6} \mathrm{O}$ grains can be seen. The selected area electron diffraction (SAED) pattern (the inset of Fig. 1) reveals roughly equiaxed grains with random orientations separated by high-angle grain boundaries (GBs) (Fig. 1). High-resolution TEM observations (not shown here) display sharp GBs without any amorphous and crystalline interfacial phases.

To explore the possible phase transitions induced by the nanoindentation, Raman spectroscopy was employed to characterize the residual indentation impressions of $\mathrm{B}_{6} \mathrm{O}$. Figure 2 shows the typical Raman spectra in the range of $200-2000 \mathrm{~cm}^{-1}$ acquired from the pristine and residual indented region of $\mathrm{B}_{6} \mathrm{O}$. The inserted SEM image shows the residual indentation at a load of $1 \mathrm{~N}$. A number of characteristics Raman bands from the pristine $\mathrm{B}_{6} \mathrm{O}$ reflect the complex atomic structure of $\mathrm{B}_{6} \mathrm{O}$. In low frequency region, the peak with uncertain origin is located at $262 \mathrm{~cm}^{-1}$ [16]. The bands at $373 \mathrm{~cm}^{-1}$ is associated with the motion of O-O pairs and the $499.5 \mathrm{~cm}^{-1}$ is related to the symmetric stretching of the O-O pairs [17]. The peak around $545 \mathrm{~cm}^{-1}$ is attributed to a motion of icosahedra boron atoms about oxygen atoms at 
ends of the each chain $[17,18]$. In high frequency region, the multiple bands at $734 \mathrm{~cm}^{-1}, 838$ $\mathrm{cm}^{-1}, 882 \mathrm{~cm}^{-1}, 1017 \mathrm{~cm}^{-1}, 1089 \mathrm{~cm}^{-1}, 1134 \mathrm{~cm}^{-1}$ and $1178 \mathrm{~cm}^{-1}$ have assigned to intra-and inter-icosahedral vibrations of boron atoms [16-18]. A part from the vibration modes of $\mathrm{B}_{6} \mathrm{O}$, the additional peaks at $335 \mathrm{~cm}^{-1}, 411 \mathrm{~cm}^{-1}$ and $516 \mathrm{~cm}^{-1}$ might be associated with oxygen deficiency in $\mathrm{B}_{6} \mathrm{O}$ and a weak band at $1285 \mathrm{~cm}^{-1}$ was attributed to unreacted boron oxide $\left(\mathrm{B}_{2} \mathrm{O}_{3}\right)$ [18]. A broad peak between 600 to $700 \mathrm{~cm}^{-1}$ is the cause of strong fluorescence $(\mathrm{F})$ by $633 \mathrm{~nm}$ (red) laser used in this study [17]. Compared with the Raman spectrum of the assintered $\mathrm{B}_{6} \mathrm{O}$, the spectrum obtained from the center of a residual impression shows the obvious changes in the Raman intensity and peak position (Fig. 2). The considerable peak broadening and red shift of the intra-and inter-icosahedral vibrations indicate that certain structure disorder associated with the $\mathrm{B}_{12}$ icosahedra is introduced by the nanoindentaion experiment. However, no additional or disappearance of $\mathrm{B}_{6} \mathrm{O}$ Raman bands can be found, which appears to be inconsistent with previously reported diamond anvil cell (DAC) experiment in which single crystal rhombohedral $\mathrm{B}_{6} \mathrm{O}$ is observed to transform into an amorphous $\mathrm{B}_{2} \mathrm{O}_{3}$ and a glassy boron phase under quasi-static pressure of $90 \mathrm{GPa}$ [19]. Since the nanoindentation contact pressure of $30-40 \mathrm{GPa}$ is significantly lower than that of the DAC experiment, it is apparently insufficient to cause the global phase transition of $\mathrm{B}_{6} \mathrm{O}$ and, instead, only produce local structural changes accompanying with the inelastic deformation driven by shear components.

In order to verify the structural transformation caused by nanoindentation, focused ion beam (FIB) milling was employed for the preparation of cross-sectional TEM specimens from the residual indentation of $\mathrm{B}_{6} \mathrm{O}$. The detailed procedure for the lift-out technique using FIB milling has been described in our previous report [15]. The low magnification brightfield and dark-field scanning transmission electron microscopy (STEM) images of $\mathrm{B}_{6} \mathrm{O}$ beneath the indenter region show several crack regions and deformation shear bands with 
variations in contrast, which are indicated with black and white arrow heads (Figs. 3(a) and (b)). Moreover, a number of dislocations, which are rarely seen in the as-prepared samples, appear in the vicinity of the deformation bands and micro-cracks, suggesting that the conventional dislocation plasticity is involved into the indentation deformation besides microcracks and shear bands. The deformation shear bands usually have a width of $\sim 1-3 \mathrm{~nm}$ and length of 200-300 nm. High-resolution STEM reveals the loss of lattice fringes in the bands (Fig. 3(c)). The fast Fourier transform (FFT) pattern taken from the band shows a diffused halo without any crystalline diffraction spots, which confirms the amorphous nature of the shear band (Inset B). By contrast, FFT patterns taken from both sides of the band reveals the parent crystal structure of [10 $\overline{1} 1]$ rhombohedral $\mathrm{B}_{6} \mathrm{O}$ (Inset A and C) (Fig. 3(c)). The angular mismatch between the lattice fringes from both sides of the amorphous band is smaller than $1^{\circ}$. This observation suggests that mode-I-type displacements do not play a marked role in the formation of the amorphous bands, which is consistent with the fact that the width of the amorphous zone does not change substantially along the length of the zone. Instead, the lattice shift of the two-side crystals along the narrow zone indicates that the amorphous band is produced by localized mode II or mode III shear instabilities. All the STEM images were taken by tilting to nearly perfect alignment on both sides of amorphous band, the possibility of diffused grain boundaries and local melting into amorphous phase can be ruled out. Chemical analysis of the amorphous and crystalline $\mathrm{B}_{6} \mathrm{O}$ regions was carried out using STEM electron energy loss spectroscopy (STEM-EELS). No detectable compositional difference in the boron-to-oxygen ratios between the two regions can found, indicating that the amorphization does not result from the chemical decomposition of $\mathrm{B}_{6} \mathrm{O}$ or pressureinduced chemical reaction (Fig. 3(d)). Thus, we suggest that the observed nanoscale amorphous shear bands occurred as solid state phase transformation during nanoindentation deformation, similar to those in $\mathrm{B}_{4} \mathrm{C}$ [20-22]. 
Shear induced amorphization has been observed in many inorganic materials [23-26]. However the underlying mechanisms remain to be poorly known. Fig. 4(a) is a BF-STEM image that shows dislocations loops taken from one end of the amorphous band. The dislocation loops are indicated by a black T and inverted $\perp$ (Fig. 4(a)). High lattice disorder can be observed in the regions of the dislocation loops, indicating that the lattice collapse of the crystals lattice is related to the dislocations accumulation during shear sliding. The Burgers vectors of these dislocations fall on crystallographic plane $(0 \overline{1} 11)$. The preferential amorphization plane is probably originated from the large elastic anisotropy and the large bonding length difference among B-B $(0.14 \mathrm{~nm})$, B-O $(0.18 \mathrm{~nm})$ and $\mathrm{O}-\mathrm{O}(\sim 0.3 \mathrm{~nm})$ in $\mathrm{B}_{6} \mathrm{O}$ [7, 27-28]. Since the (0111) crystal plane contains relatively weak O-O bonds, it may be easy to slide and the breaking of the $\mathrm{O}-\mathrm{O}$ chains may lead to the amorphization of $\mathrm{B}_{6} \mathrm{O}$, as shown in the schematic diagram (Fig. 4(b)).

Inevitable micro-scale flaws, such ask micro-cracks and inclusions, introduced by sintering, usually lead to ceramics failure in a brittle manner without any plasticity at a low applied stress. However, under extreme loading conditions (such shock loading [20, 29], small volume and confined deformation (indentation [21, 15] and diamond anvil cells [10])), the cracking can be completely suppressed and the materials can exhibit their intrinsic deformation behavior by either dislocation plasticity or phase transition. For the super-hard materials, such as diamond, $\mathrm{B}_{4} \mathrm{C}$ and $\mathrm{BO}_{6}$, the strong covalent bonds may lead to very high Peierls stresses for dislocation motion at low temperatures. Thus, those materials cannot plastically deform by pure dislocations even the cracking is suppressed. If there is a relatively weak crystallographic plane for shearing, it may cooperatively slip with or without the assistance of dislocations. This kind of rigid slip often results in the local shear amorphization because of the break of local order and translational symmetry [22]. 
$\mathrm{B}_{6} \mathrm{O}$ has ultrahigh hardness but very low fracture toughness because of the easy formation and propagation of cracks. Traditionally, the brittleness of the high-strength ceramics is often attributed to the intrinsic fragility of chemical bonds that are strong but not flexible to tolerate deformation. However, the detailed experimental failure process of these chemical bonds is less known. The formation of nano-sized amorphous bands in $\mathrm{B}_{6} \mathrm{O}$, subjected to shearing, offers new insights of the brittle failure of the super-hard materials at a much lower stress than their theoretical strength. The brittleness is not from the direct failure of the rigid bonds under model I-type normal stresses and, instead, caused by the shear induced structure instability. Shear deformation usually leads to plastic strains and hence enhances materials ductility. However, in highly isotropic materials, the preferential sliding along weakly bonded atomic planes may result in local structure collapse and failure. This type of shear induced amorphization and materials failure is probably a popular phenomenon in high-strength materials with significant structural and elastic anisotropy.

\section{Acknowledgments}

This work is sponsored by JST-CREST "Phase Interface Science for Highly Efficient Energy Utilization" and "World Premier International (WPI) Center Initiative for Atoms, Molecules and Materials," MEXT, Japan. 


\section{References}

[1] A. R. Badzian, Appl. Phys. Lett. 53 (1988) 2495.

[2] D. He, Y. Zhao, L. Daemen, J. Qian, T. D. Shen, T. W. Zerda, Appl. Phys. Lett. 81 (2002) 643.

[3] C. Chen, D. He, Z. Kou, F. Peng, L. Yao, R. Yu, Y. Bi, Adv. Mater. 19 (2007) 4288.

[4] M. Herrmann, I. Sigalas, M. Thiele, M. M. Muller, H. J. Klebbe, A. Michaelis, Int. J. Refract. Met. H. 39 (2013) 53.

[5] S. Veprek, R. F. Zhang, A. S. Argon, J. Superhard Mater. 33 (2011) 60.

[6] H. Hubert, B. Devouard, L. A. Garvie, M. O’Keeffe, P. R. Buseck, W. T. Petuskey, and P. F. McMillan, Nature 391 (1998) 376.

[7] M. Kobayashi, I. Higashi, C. Brodhag, F. Thevenot, J. Mater. Sci. 28 (1993) 2129.

[8] F. Gao, L. Hou, Y. He, J. Phys. Chem. B 108 (2004) 13069.

[9] G. Fanchini, J. W. McCauley, M. Chhowalla, Phys. Rev. Lett. 97 (2006) 035502.

[10] X. Q. Yan, Z. Tang, L. Zhang, J. J. Guo, C. Q. Jin, Y. Zhang, T. Goto, J. W. McCauley, M. W. Chen, Phys. Rev. Lett. 102 (2009) 075505.

[11] V. L. Solozhenko, O. O. Kurakevych, V. Z. Turkevich, D. V. Turkevich, J. Phys. Chem. B $112(2008) 6683$.

[12] H. F. Rizzo, W. C. Simmons, H. O. Bielstein, J. Electrochem. Soc. 109 (1962) 1079.

[13] C. Brodhag, F. Thevenot, J. Less. Comm. Met. 117 (1986) 1.

[14] T. Akashi, T. Itoh, I. Gunjishima, H. Masumoto, T. Goto, Mater. Trans. 43 (2002) 1719.

[15] J. J. Guo, K. Wang, T. Fujita, J. W. McCauley, J. P. Singh, M. W. Chen, Acta Mater. 59 (2011) 1671.

[16] H. Werheit, U. Kuhlmann, J. Solid State Chem. 133 (1997) 260.

[17] V. L. Solozhenko, O. O. Kurakevych, P. Bouvier, J. Raman Spectrosc. 40 (2009) 1078.

[18] T. L. Aselage, D. R. Tallant, D. Emin, Phys. Rev B 56 (1997) 3122. 
[19] Z. Wang, Y. Zhao, P. Lazor, H. Annersten, and S. K. Saxena, Appl. Phys. Lett. 86 (2005) 041911.

[20] M. W. Chen, J. W. McCauley, K. J. Hemker, Science 299 (2003) 1563.

[21] D. Ge, V. Domnich, T. Juliano, E. A. Stach, Y. Gogotsi, Acta Mater. 52 (2004) 3921.

[22] K. Madhav Reddy, P. Liu, A. Hirata, T. Fujita, M. W. Chen, Nat. Commun. 4 (2013) 2483.

[23] K. J. Kingma, C. Meade, R. J. Hemley, H. K. Mao, D. R. Veblen, Science 259 (1993) 666.

[24] A. J. Gratz, L. D. Deloach, T. M. Clough, W. J. Nellis, Science 259 (1993) 663.

[25] K. Minowa, K. Sumino, Phys. Rev. Lett. 69 (1992) 320.

[26] P. Cordier, J. C. Doukhan, J. Peryonneau, Phys. Chem. Miner. 20 (1993) 176.

[27] R. F. Zhang, Z. J. Lin, Y. S. Zhao, S. Veprek, Phys. Rev B 83 (2011) 092101.

[28] T. E. Letsoalo, J. E. Lowther, J. Superhard Mater. 33 (2011) 19.

[29] M. W. Chen, J. W. McCauley, D. P. Dandekar, N. K. Bourne, Nature Mater. 5(2006)614. 


\section{Figure list}

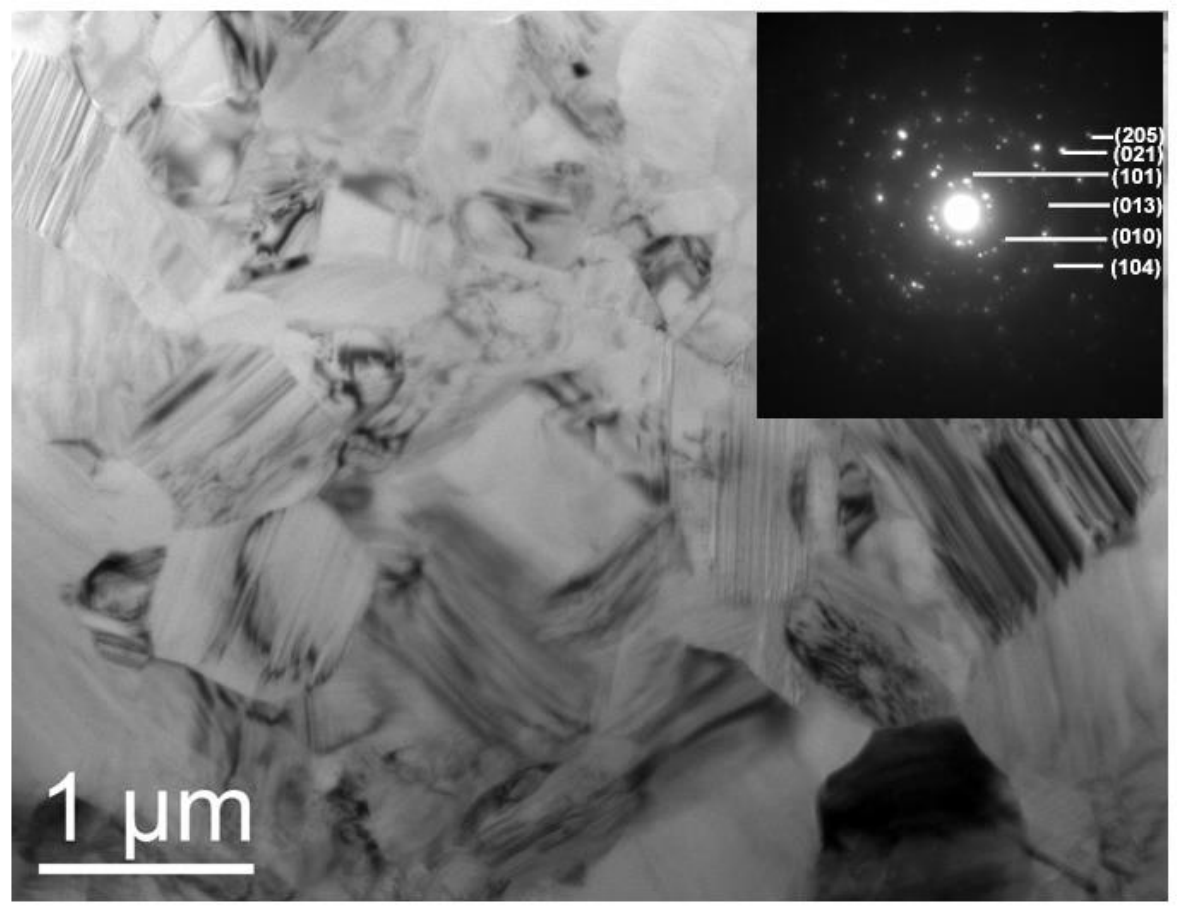

Figure 1. A typical TEM image of polycrystalline $\mathrm{B}_{6} \mathrm{O}$ synthesized at $60 \mathrm{MPa}$ and $2173 \mathrm{~K}$ for $1 \mathrm{~h}$. The SAED pattern of $\mathrm{B}_{6} \mathrm{O}$ is inserted to the TEM image. 


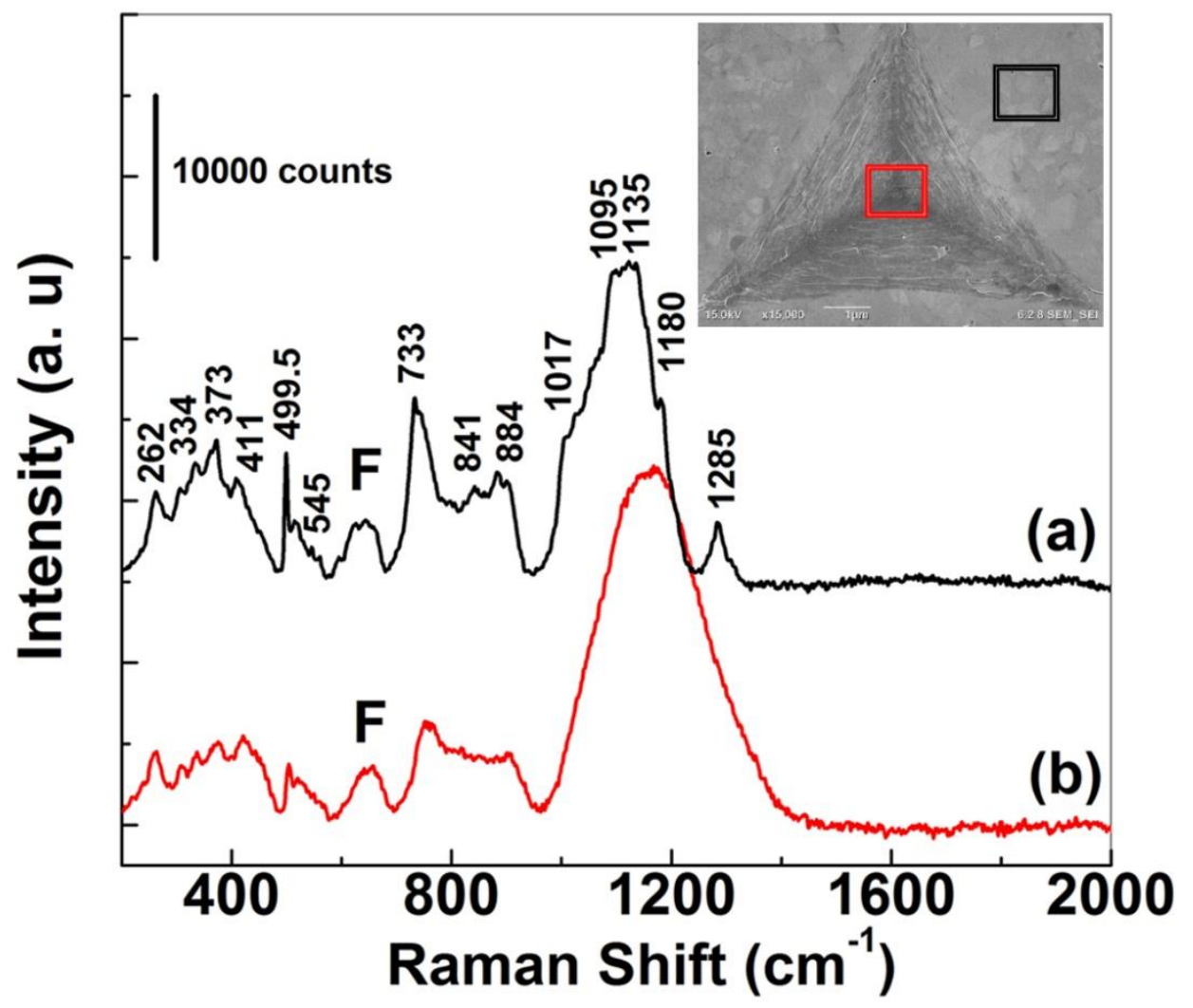

Figure 2. Representative Raman spectra of $\mathrm{B}_{6} \mathrm{O}$ (a) pristine surface and (b) residual indentation obtained using an argon ion laser with excitation wavelength of $633 \mathrm{~nm}$. Inset SEM image shows the Berkovich indented impression at a load of $1 \mathrm{~N}$. 

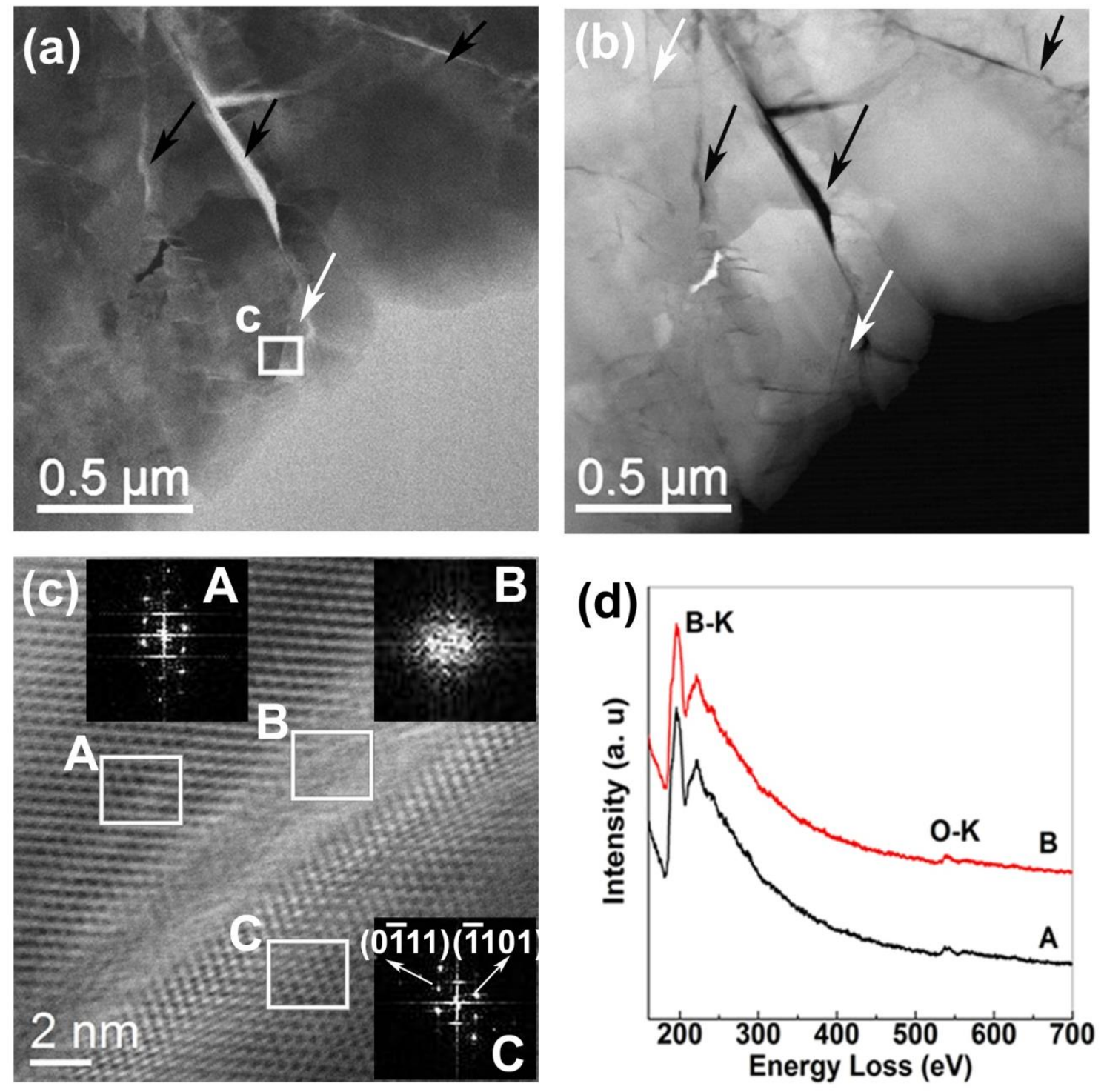

Figure 3. (a) Bright field (BF) STEM and (b) Dark field (DF) STEM images showing several cracks (black arrow head) and shear bands (white arrow head) beneath the indenter. (c) zoom-in BF-STEM image of the amorphous band along the [1011] direction of crystalline $\mathrm{B}_{6} \mathrm{O}$ (Inset FFT pattern A). The loss of lattice fringes in the band indicates the $\mathrm{B}_{6} \mathrm{O}$ amorphization (Inset FFT pattern B). (d) STEM-EELS spectra obtained from (A) crystalline lattice and (B) amorphous $\mathrm{B}_{6} \mathrm{O}$. 

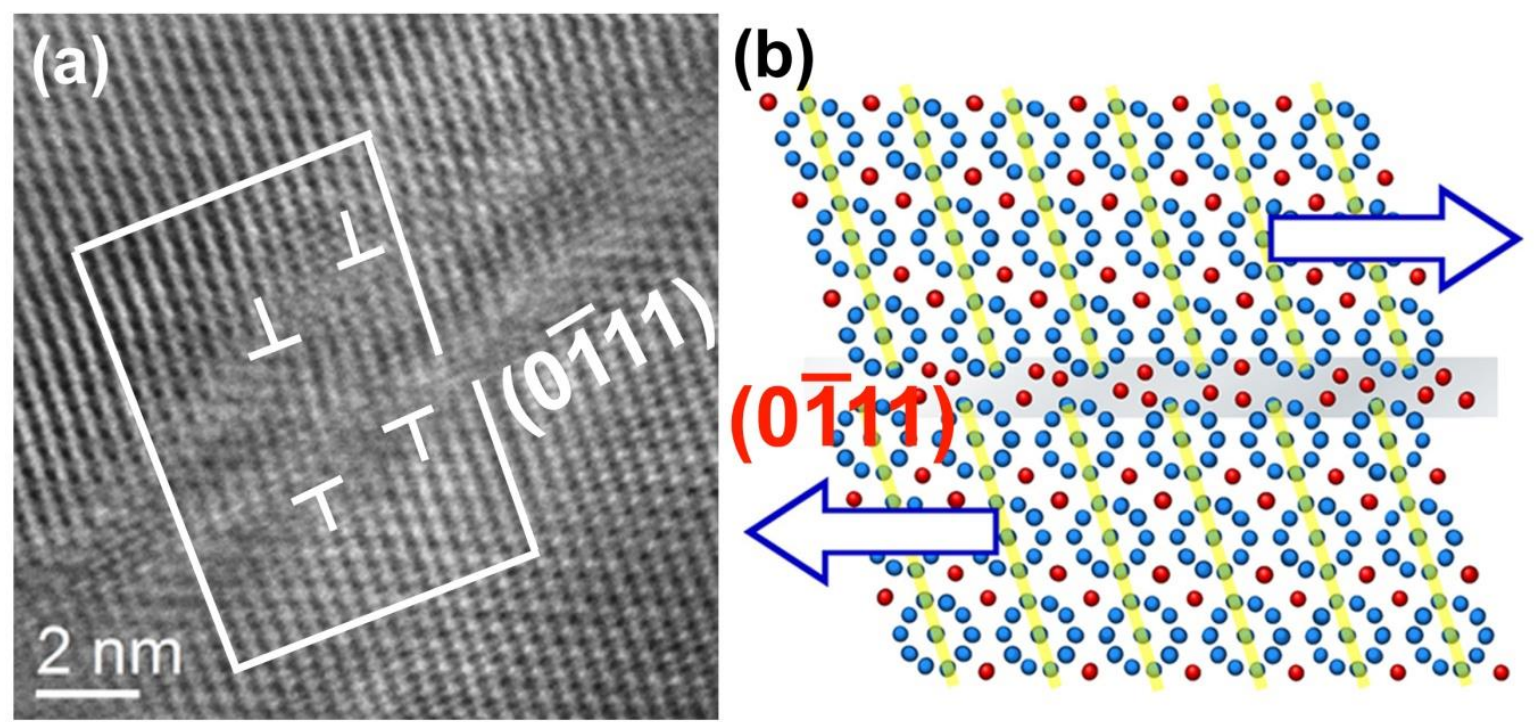

Figure 4. (a) BF-STEM image of $\mathrm{B}_{6} \mathrm{O}$ shows the dislocations loops at the end of the amorphous shear band. (b) A schematic of localized softening of amorphization $\mathrm{B}_{6} \mathrm{O}$ along the sliding plane $(0 \overline{1} 11)$. The blue color is boron and red color is oxygen atoms. 